UDC 004.93

\title{
No-Reference Quality Assessment of an Image Resizing Algorithms
}

\author{
David G. Asatryan \\ Institute for Informatics and Automation Problems of NAS RA \\ Russian-Armenian University \\ e-mail: dasat@ipia.sci.am
}

\begin{abstract}
In this paper, a No-Reference method is proposed for quality assessment of an image resizing methods based on interpolation algorithms. Quality refers to the image blur. To this end, it is proposed to use a previously developed measure based on a statistical assessment of the Weibull distribution shape parameter, adopted as a model for gradient magnitude of an image. The results of numerical experiments are presented that allow us to evaluate and compare the quality of various image resizing algorithms.

Keywords: Image resizing, Interpolation, Blur, Quality assessment, Gradient magnitude, Weibull distribution.
\end{abstract}

\section{Introduction}

Image resizing (scaling) methods are widely used in various problems of theory and technique of image processing. An image, once obtained in some way, can undergo multiple changes to meet the needs of the practice, in particular, resizing in one direction or another. A variety of needs and a huge market have led to the need to develop effective and convenient algorithms and resizing tools suitable for use in a wide range of technical applications, from space research to mobile communications.

However, the use of any resizing algorithms changes the content of the image, thereby affecting its quality. Moreover, each mathematical method that underlies the resizing algorithm works well for a certain class of images and may not be suitable for other classes. This explains the wide variety of mathematical methods developed to date and implemented in the form of software modules and systems, including the widely known image processing systems. In parallel, image processing specialists have long performed comparative studies of the quality of resizing methods and proposed appropriate recommendations for their use (see, for example, [1]). 
To select the appropriate method for resizing images of a given class, it is necessary to apply a certain measure to assess the quality of the resulting image. At the same time, depending on the image information available to the user and the problem to be solved, its quality can be characterized in different ways. For example, if there is an original, by resizing which a test image is obtained, then the quality of the latter can be estimated by the degree of the observed distortion, which inevitably appears when resizing. However, in the absence of the original (standard) or any other additional information about the original, one has to use only the information that can be extracted from the image by analyzing its available properties. The literature suggests many types of image quality measures, known as standardless or NoReference.

This work is devoted to the application of the previously developed No-Reference measure for assessing image quality using its structural properties.

\section{A Brief Overview of the Problem Status}

Quality assessment algorithms are divided into three categories, depending on the completeness of the information used for this:

1. Full use of standards (Full Reference),

2. Partial use of standards (Reduced Reference),

3. Lack of standards (No-Reference).

With Full Reference, it is assumed that the latter is of an acceptable high quality, and the test image is compared with it by assessing their discrepancy. Many such measures have been proposed in the literature, and we restrict ourselves to a reference to the papers [2-4], which are based on the use of various structural properties of an image. We also point out the survey papers [5-6], in which other measures for assessing an image quality are considered.

An important feature of the applicability of the comparison method with the standard, related to the need to assess the similarity of images with different sizes, should be noted. In [7], for this problem, we used the method [3] based on the Weibullian model of gradient magnitude, which is briefly described below.

With the partial use of standards, they are based on certain properties or features that allow you to make decisions regarding the quality of the test image.

The most difficult category is represented by No-Reference algorithms that do not require specific meaningful information about the test image. The main difficulty in this case is due to the fact that there are a huge number of types of distortion to which the image can be subjected, and often nothing is known about the specific type of distortion of the test image. Therefore, creating algorithms that work equally well for all types (or at least for a large number of types) of distortion is an important, but rather difficult task. In this paper, we restrict ourselves to a reference to the review paper [6], which is devoted to the comparative analysis of various known No-Reference methods for assessing an image quality.

It should be noted that in the literature the quality of a resized image is often evaluated visually, based only on a subjective analysis of the observed distortions. For example, Figure 1 shows the original image from the database [8] and its fivefold reduced sample (images with equal sizes are shown in the text to save space). Distortions are clearly visible on the resized image; however, it is impossible to visually assess the degree of these distortions, which emphasizes the urgency of developing and studying formal methods for this task. 


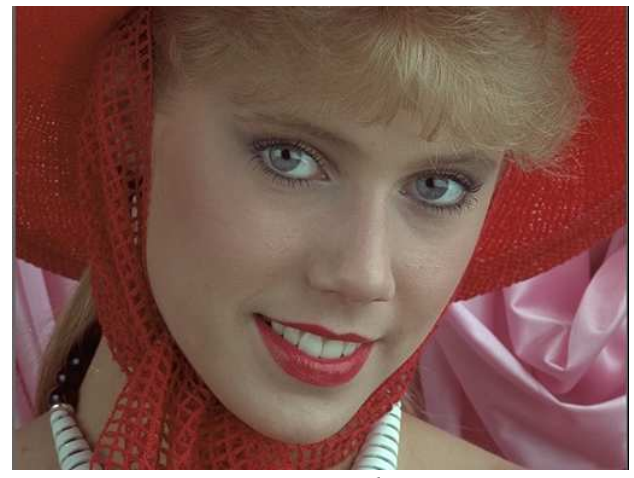

Original

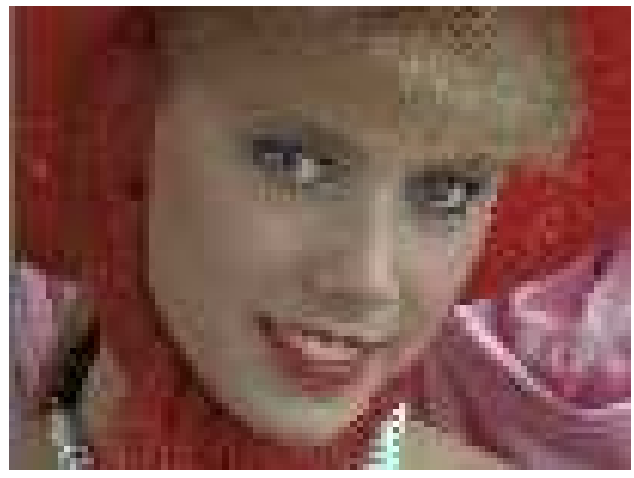

Resized

Fig. 1. Illustration of distortion when resizing.

The present paper is devoted to a comparative analysis of the quality of some of the most commonly used resizing algorithms based on well-known methods of numerical interpolation, using the recently proposed and thoroughly studied No-Reference measure based on the use of image structural properties [9-10]. As shown in [9], the Weibull distribution shape parameter can be used as a measure of image blur, and in [10] the ability of this measure to evaluate the image quality for other types of distortion is shown. We used the results of [8], which describes the TID2013 image database containing 3000 images obtained from 25 originals, distorted by 24 different types with five levels each. In this work, the results of an extensive experiment on visual assessment of quality according to a point system by a large number of people in different countries are presented. As a result of processing these data, each of the 3000 images is assigned a numerical rating of the quality estimated visually (Mean Opinion Score - MOS).

Using the TID2013 database allows you to evaluate the quality of any procedure used both in the task of assessing image quality with the Full Reference procedures, and in the NoReference situation. An example of applying the approach using the No-Reference measure is [10].

In this article, this procedure is used to assess the quality of the image obtained as a result of resizing the original, which allows us to make certain judgments about the applicability of some resizing methods.

\section{Quality Assessment Method and Experimental Results}

Mathematical model. Following [3], we will accept for the magnitude of the image gradient a model based on the Weibull distribution, the density of which is given by the formula

$$
f(x ; \lambda, \eta)=\frac{\eta}{\lambda}\left(\frac{x}{\lambda}\right)^{\eta-1} \exp \left[-\left(\frac{x}{\lambda}\right)^{\eta}\right], x \geq 0,
$$

where $\eta>0$ is the shape parameter, $\lambda>0$ is the scale parameter.

The magnitudes of the gradients are estimated using the Sobel operator, and the distribution parameters are estimated from the totality of all the magnitudes (1).

In [9], it was proposed to take the parameter value as a measure of image blur (the larger the measure value, the greater the blur). Details of the procedure can be found in [8-9].

Description of experimental material. For the experiments, the originals of 25 images of the base [8] were selected, some of which are shown in Fig. 2. 


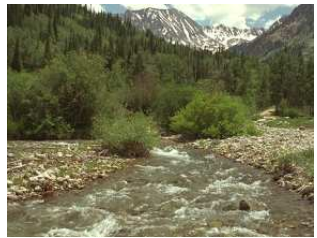

1,219

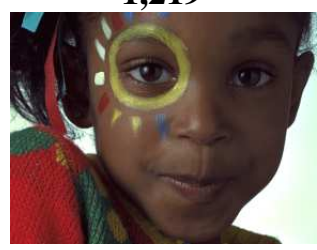

0,684

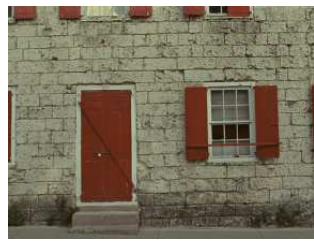

1,086

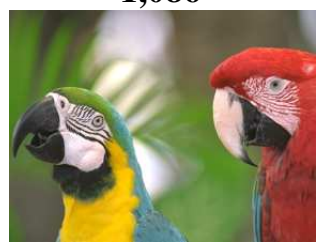

0,624

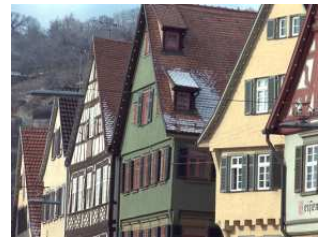

1,043

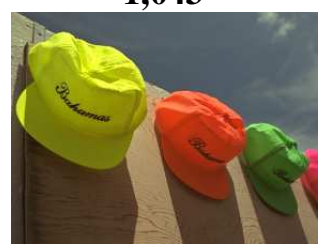

0,601

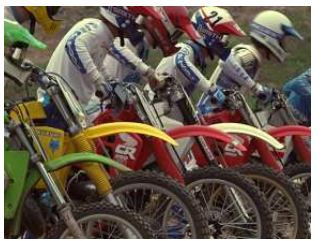

1,042

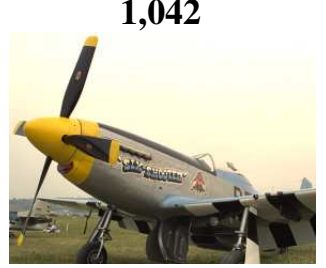

0,556

Fig. 2. Original images of the TID2013 base with high measure values (upper row) and with low measure values (lower row).

Resizing was performed using the well-known interpolation algorithms implemented in many popular graphic editors: Lanczos, Nearest Neighbor, Bilinear, Bspline, Gaussian. The following values were selected for the resizing factor (RF): $0.25,0.5,0.66,0.75,1,1.25,1.5,1.75$ and 2.0.

Before analyzing the results, we make one important point. According to the methodology [9] of the No-Reference estimation of blurriness, the more blurry the image, the greater the measure value. It was noted that for sufficiently blurry images, this value approximates to " 2 " and only slightly exceeds this value in certain cases, and for images with a fairly clearly defined structure, this value is much less than 2. However, it should also be noted that the value of the measure for an arbitrary image depends on its structure and specific content, and it can hardly be interpreted as an absolute estimate of blur. Therefore, when considering the value of the measure obtained for a fixed image, the problem arises of studying the dependence of the quality of the images obtained, perhaps, by various transformations of this sample, including when resizing it.

The results of numerical experiments are as follows:.

1. Figure 2 shows the original images of the TID2013 database with the lowest and highest measure values (indicated under the corresponding images). Examining these images and visually assessing the degree of their blurring and comparing the corresponding values of the measure, we can note their correspondence with a certain degree of reliability.

2. Let's consider the first image in the list of the TID2013 database (it is placed second in Figure 2 in the upper row) and perform the resizing operation according to the selected algorithms. Figure 3 shows graphs of the dependence of the blur measure on the RF. Here, the abscissa axis shows the resizing levels from 1 to 9 , corresponding to the above values of the resizing factor from 0.25 to 2.0.

The dependency curves show that all five resizing methods behave approximately the same way, i.e., as the RF increases, the blur generally decreases, and when the RF approaches maximum values, the degree of blur more or less stabilizes (with the exception of the Bilinear method, in which the decrease in blur is significant, which apparently appears due to the features of this image).

It should be noted that the trend noted above is a formal confirmation of the correspondence between the visual perceptions of the effect of reducing blur due to the smoothing of the picture of intensity transitions in the image. It is also important to note that for $\mathrm{RF}<1$ and $\mathrm{RF}>1$, the branches of the curves are located differently relative to each other. In other words, for some RF values, one resizing method may have an advantage, while for other RF values, another. 


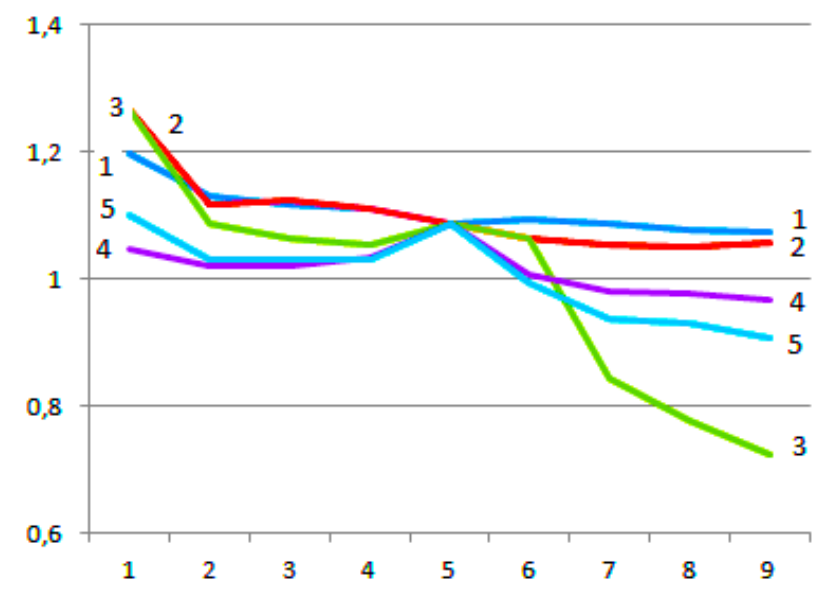

Fig. 3. Dependence of a fixed image blur on resizing method.
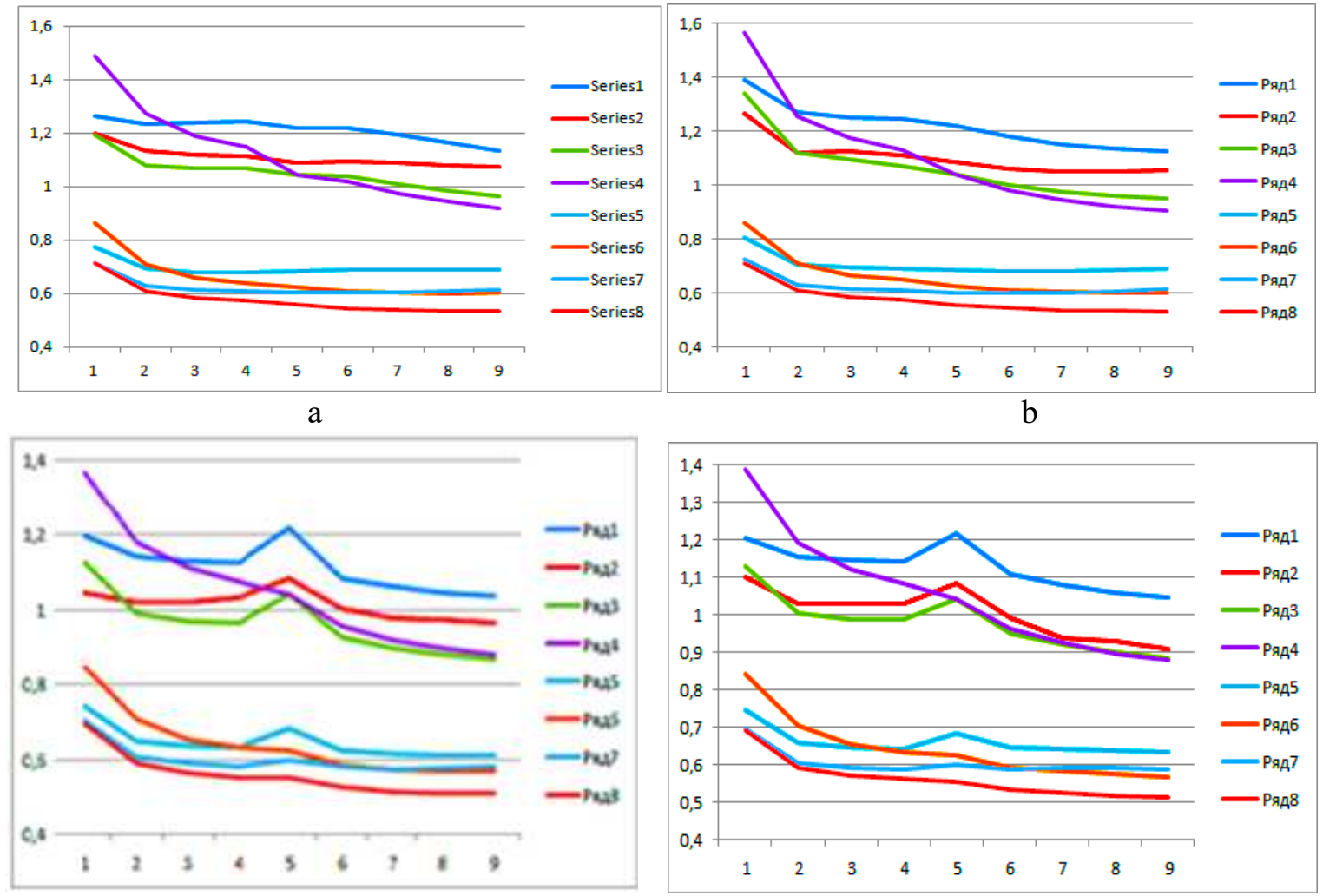

c

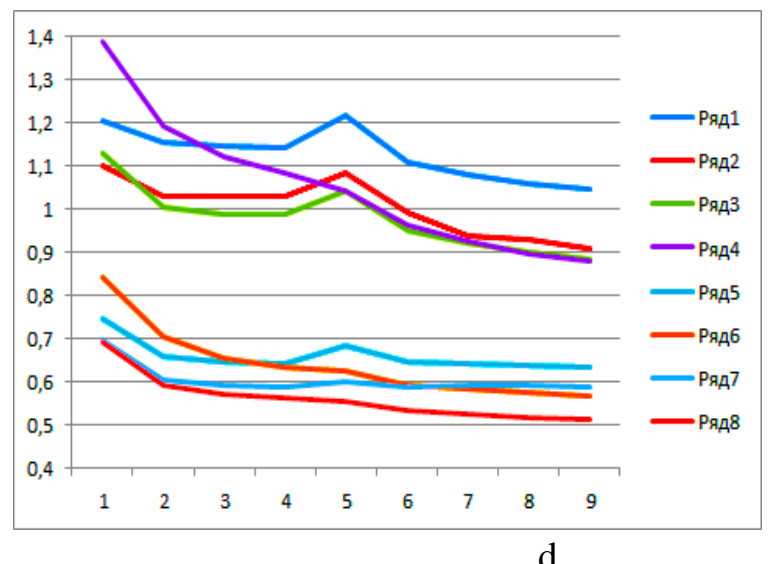

Fig. 4. Dependence of blur on the resizing algorithm for the images shown in Fig. 2, a - Lanszos algorithm, b - Nearest Neighbor, c - Bilinear, d - Bspline.

3. It is of interest to compare the nature of the change in blur from RF for images with different initial blur values. Figure 4 shows the graphs of the dependence of the blur when resizing eight images from the TID2013 database, shown in Fig. 2. We note that, firstly, the same properties hold as above. In addition, despite the fact that the results are presented only for four resizing methods (similar results are also obtained for other methods); the nature of the dependence is preserved. However, there is a difference in the values and stabilization rate of the degree of 
blurring depending on its value in the absence of resizing (i.e., at RF $=1$ ). In other words, the higher the degree of blur of the original, the less this image is subject to blur when resizing.

\section{Conclusions}

The paper proposes a method of No-Reference estimation of the quality of image resizing algorithms based on the application of the previously developed image blur estimation technique. The technique is based on modeling the image gradient magnitude data using a two-parameter Weibull distribution. In this case, a statistical estimation of the shape parameter of this distribution is used as a blur measure. It is shown that this measure allows you to compare the quality of various resizing methods, which are based on numerical interpolation methods.

It can also be noted that the application of the obtained results in practice can be more useful in combination with the results of assessing the similarity of the resized image to the original, carried out by adequate methods.

\section{References}

[1] A. Parker, R. V. Kenyon and D. Troxel, "Comparison of interpolating methods for image sampling”, IEEE Transactions on Medical Imaging, vol. M1-2, no. 1, p. 31-39, 1983.

[2] Z.Wang, A.C.Bovik, "Modern image quality assessment",Synthesis Lectures on Image, Video, and Multimedia Processing,vol. 2, no. 1, pp. 1-156, 2006.

[3] D.Asatryan, K. Egiazarian, 'Quality assessment measure based on image structural properties",Proc. of the International Workshop on Local and Non-Local Approximation in Image Processing, Finland, Helsinki, 19-21 August, pp. 70-73, 2009.

[4] W.Xue,L.Zhang, X.Mou and A.C. Bovik, "Gradient magnitude similarity deviation: A highly efficient perceptual image quality index",IEEE Transactions on Image Processing, vol. 23, no. 2, pp.684-695, 2014.

[5] O.Sebastian and S.Arkadiusz,'The survey of subjective and objective methods for quality assessment of 2D and 3D images", Theoretical and Applied Informatics,vol. 26,no. 1, 2, pp. $39-67,2014$.

[6] В.В.Старовойтов и Ф.В. Старовойтов, “Сравнительный анализ безэталонных мер оценки качества цифровых изображений”, Системный анализ и прикладная информатика, № 1, сс. 24-32, 2017.

[7] D.G.Asatryan, "Gradient-based technique for image structural analysis and applications", Computer Optics, vol. 43, no. 2, pp. 245-250, 2019.

[8] N.Ponomarenko, L. Jin, O. Ieremeiev, V. Lukin, K. Egiazarian, J. Astola, B.Vozel, K. Chehdi, Carli, F. Battisti, et al. "Image database TID2013: Peculiarities, results and perspectives”, Signal Processing: Image Communication,vol.30, pp. 57-77, 2015.

[9] Д. Г.Асатрян, Оценивание степени размытости изображения путём анализа градиентного поля,Компьютерная оптика,вып. 41, №6, сс. 957-962,2017.

[10] D. A. Asatryan, "Novel technique for no-reference image quality assessment",Proceedings of International Conference on Computer Science and Information Technologies, Yerevan, Armenia,pp. 201-203, 2019.

\section{Submitted 10.05.2019, accepted 15.11.2019.}




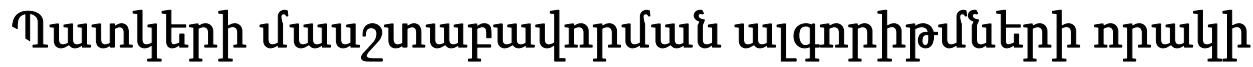

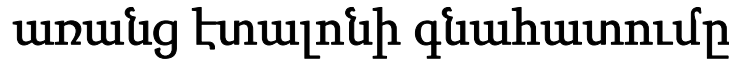

\author{
Tuulhp 9. Uuuunpjuid

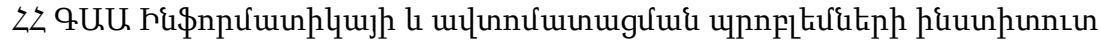

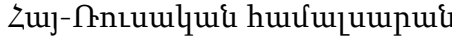 \\ e-mail: dasat@ipia.sci.am
}

\section{Uরựnนhnư}

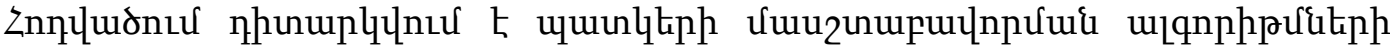

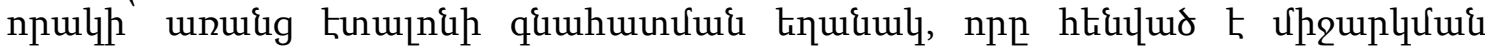

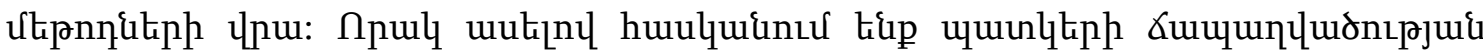

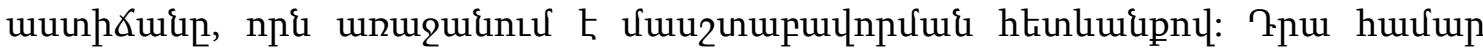

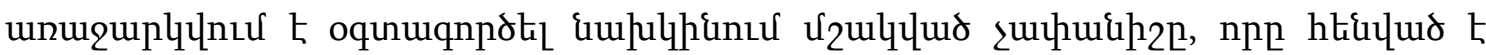

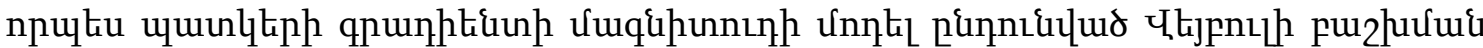

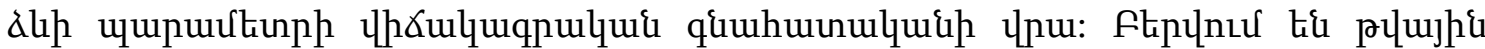

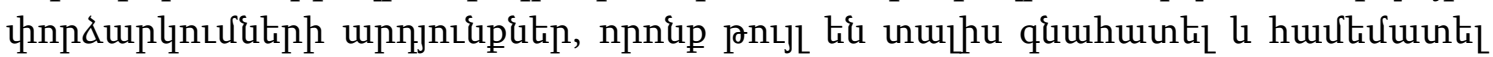

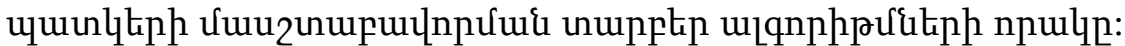

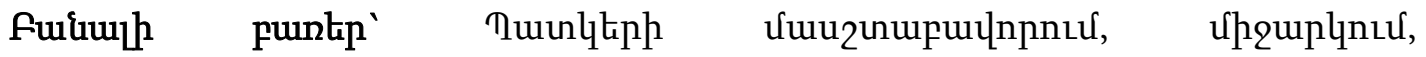

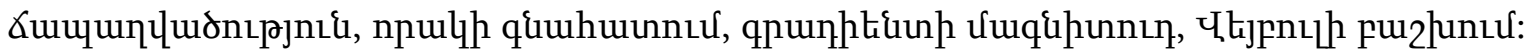

\section{Безэталонное оценивание качества алгоритмов масштабирования изображения}

\author{
Давид Г. Асатрян \\ Институт проблем информатики и автоматизации НАН РА \\ Российско-Армянский университет \\ e-mail:dasat@ipia.sci.am
}

\begin{abstract}
Аннотация
В статье рассматривается метод безэталонного оценивания качества алгоритмов масштабирования изображения, основанный на методах интерполирования. Под качеством понимается степень размытия изображения, вызванного масштабированием. Для этого предлагается использовать разработанную ранее меру, основанную на статистическую оценку параметра формы распределения Вейбулла, принятого в качестве модели для магнитуды градиента изображения. Приводятся результаты численных экспериментов, которые позволяют оценивать и сравнивать качество различных алгоритмов масштабирования изображения.

Ключевые слова. Масштабирование изображения, интерполирование, размытость, оценивание качества, магнитуда градиента, распределение Вейбулла
\end{abstract}

